\title{
O Julgamento Perante Juízes do Povo e o Real Alcance da Expressão “Justiça”
}

\author{
Judgment Before the People's Judges and the Real Scope of the Expression "Justice"
}

\author{
Nilsen Aparecida Vieira Marcondes
}

Universidade de Taubaté, Programa de Pós-Graduação Stricto Sensu em Desenvolvimento Humano.

E-mail: nilsenmarcondes@gmail.com

\begin{abstract}
Resumo
Este artigo tem como objetivo refletir acerca do julgamento perante juízes do povo e o real alcance da expressão "justiça". Trata-se de um estudo de abordagem teórica, básica e qualitativa, exploratória e bibliográfica, porque teve como sustentação o levantamento de literatura pertinente à temática abordada. Portanto, para respaldar a construção deste artigo e reflexão sobre os conceitos e temas ora apresentados se utilizou de uma pesquisa bibliográfica. Os resultados apontam que tratar da temática "Tribunal do Júri” possibilita a abertura de importantes espaços reflexivos sobre questões que envolvem: o sigilo dos votos; a motivação das decisões; a duração razoável do processo; o silêncio; a inexigibilidade de autoincriminação; bem como a proibição das provas ilícitas. Conclui-se que retomadas contínuas de estudos sobre a temática são pertinentes na medida em que trazem luz e ampliam a compreensão da importância de se reconhecer que o julgamento perante juízes do povo se configura, também, como uma das importantes estratégias de busca por justiça na ambiência jurídica.
\end{abstract}

Palavras-chave: Tribunal do Júri. Alcance de Justiça. Revisão Teórica.

\begin{abstract}
This article aims to reflect on the judgment before people's judges and the actual scope of the phrase "justice". It is a theoretical, basic and qualitative, exploratory and bibliographical approach study, because it had as support the literature survey concerning the addressed topic . Therefore, to support the construction of this article and reflection on the concepts and themes presented here, a bibliographical research was used. The results show that dealing with the theme "Court of the Jury" allows the opening of important reflective spaces on issues that involve: the secrecy of votes; the motivation of decisions; the reasonable proceedings duration; silence; the self-incrimination unenforceability; as well as the unlawful evidence prohibition. It is concluded that continuous resumes of studies on the subject are pertinent in that they bring light and extend the understanding of the importance of recognizing that the judgment before the people's judges also constitutes one of the important strategies of searching for justice in the legal ambience.
\end{abstract}

Keywords: Jury Court. Scope of Justice. Theoretical Review.

\section{Introdução}

O objetivo deste artigo é refletir acerca do julgamento perante juízes do povo e o real alcance da expressão "justiça". Considera-se que centrar discussões em torno da instituição do Júri é relevante, principalmente, quando se verifica que são assegurados nesse processo decisório quatro princípios fundamentais, quais sejam: (i) a plenitude de defesa; (ii) o sigilo das votações; (iii) a soberania dos veredictos e (iv) a competência para o julgamento dos crimes dolosos contra a vida. E, ainda, mais relevante é tratar do assunto quando a mídia, por exemplo, ao expor casos de competência do Tribunal do Júri, forma os chamados "juízos paralelos". Entretanto, por outro lado, não se pode negar também que a liberdade de informação é um direito humano universal e fundamental e, verdadeiramente, essencial para a Democracia.

$\mathrm{Na}$ esteira da reflexão sobre um julgamento perante juízes do povo e o real alcance da expressão "Justiça" se considera também oportuno analisar o fato de que a ausência de um prazo estipulado em lei para a duração da prisão preventiva e do processo penal afronta diversos princípios e garantias constitucionais. Diante disso, emergem duas indagações: estabelecer prazos processuais, sem qualquer punição pelo descumprimento é o mesmo que insistir na "doutrina do não prazo"? A legislação infraconstitucional permite observância estrita ao princípio da "razoável duração do processo"?

E, ainda, a reflexão sobre um julgamento perante juízes do povo e o real alcance da expressão "Justiça" pode levar igualmente a tecedura de considerações sobre a seguinte questão: apesar de o texto constitucional aludir apenas ao direito de permanecer calado, o princípio da "não autoincriminação", ou "nemo tenetur se detegere" é bastante abrangente, diante disso, é importante analisar as extensões desse princípio, bem como a guarida legislativa que o defende.

Por fim, a reflexão sobre um julgamento perante juízes do povo e o real alcance da expressão "Justiça" possibilita também que se faça ponderações a respeito do princípio da inadmissibilidade das provas ilícitas, indagando-se: (i) até que ponto tal princípio pode ser considerado um valor absoluto no Direito Constitucional Brasileiro? (ii) se não, qual seria seu limite? (iii) e, em quais situações poderia ser admitida a prova 
obtida por meios ilícitos?

Diante da temática "Tribunal do Júri" e dos questionamentos decorrentes procurou-se contribuir, mediante análises reflexivas ora apresentadas, com o adensamento da literatura sobre tais realidades, objetivando-se, portanto, com este artigo realizar uma revisão teórica acerca do assunto.

\section{Desenvolvimento}

\subsection{Metodologia}

Trata-se de um estudo que se apresenta, quanto à forma de abordagem do assunto, como teórico, básico e qualitativo. Com relação aos objetivos se intitula como exploratório e, no que diz respeito aos procedimentos técnicos, caracterizase como bibliográfico, porque teve como sustentação o levantamento de literatura pertinente à temática abordada. A corrente epistemológica adotada neste estudo se pauta no construtivismo e com relação à perspectiva teórica a ser utilizada durante todo o desenvolvimento da pesquisa, a escolha foi pela investigação crítica. E por fim, quanto ao referencial analítico se utilizou como eixo para tratar do tema deste artigo a análise de conteúdo (PEROVANO, 2016).

\subsection{Discussão}

Tratar da temática "Tribunal do Júri” possibilita a abertura de espaços reflexivos sobre questões que envolvem: (i) o sigilo dos votos; (ii) a motivação das decisões; (iii) a duração razoável do processo; (iv) o silêncio; (v) a inexigibilidade de autoincriminação; (vi) bem como a proibição das provas ilícitas.

Igualmente relevante é considerar que algumas indagações complementares podem adensar a reflexão sobre a temática em questão como, por exemplo: Fatores externos ao procedimento penal do Tribunal do Júri podem influenciar a decisão pelos jurados? E o sigilo dessa votação impede que esses fatores externos sejam identificados? Quanto ao princípio da duração razoável do processo, pode-se falar da "teoria do não prazo"? A prisão cautelar, por sua vez, possui prazo? Qual a verdadeira extensão do direito constitucional de permanecer em silêncio? E por fim, qual a verdadeira extensão da inadmissibilidade das provas obtidas por meios ilícitos no processo penal brasileiro?

No que se refere ao julgamento perante juízes do povo e o real alcance da expressão "Justiça” e questão da mídia se têm, primeiramente, que um julgamento perante juízes do povo em um Estado Democrático de Direito (MEDEIROS, 2016) implica em não perder de vista que se trata de um julgamento que deve se pautar na recusa explícita de qualquer forma de opressão da pessoa, o que significa se aproximar o mais possível da verdadeira "Justiça" (MELLO; MOREIRA, 2015).

E para assegurar que intervenções opressivas sejam descartadas do cenário social, o ordenamento jurídico conta com diversos princípios e regras que, igualmente se refletem na política processual de um país (RAMIDOFF, 2017), principalmente, em um país regido pelo sistema democrático de direito, como é o caso do Brasil (MEDEIROS, 2016). Assim sendo, as intervenções mais próximas possíveis do alcance da "Justiça" estarão garantidas, ao menos no plano teórico, visto que tais princípios e regras estão positivados nas normas constitucionais e infraconstitucionais (MELLO; MOREIRA, 2015).

O princípio constitucional da dignidade da pessoa humana, por exemplo, assume uma função essencial enquanto norteadora das ações e reflexões que emergem em um processo de interpretação e de integração daquilo que se faz constar na Constituição e, principalmente, no Direito Processual Penal (RAMIDOFF, 2017).

E nesse sentido, os procedimentos adotados no Tribunal do Júri não estão imunes aos reflexos desse princípio constitucional da dignidade da pessoa humana. E ainda, bem como não estão imunes também aos reflexos de outros princípios que incidem, particularmente, no Direito Processual e Direito Penal como, por exemplo, o direito (i) ao devido processo legal; (ii) à presunção de inocência; (iii) à ampla defesa; (iv) ao contraditório; (v) à duração razoável do processo; (vi) à não autoincriminação; (vii) à igualdade entre as partes; (viii) ao juiz natural; (ix) à inafastabilidade do controle jurisdicional; (x) à publicidade; (xi) à motivação das decisões; (xii) ao duplo grau de jurisdição; (xiii) ao processo justo; e (xiv) à inadmissibilidade da prova ilícita (RAMIDOFF, 2017).

Não obstante tantos princípios, todos (i) se configuram como instrumentos garantistas e objetivam alcançar uma mesma realidade, ou seja, (ii) impedir que a pessoa seja julgada de qualquer forma dentro ou fora dos Tribunais do Júri.

Os princípios processuais penais servem como diretrizes hermenêuticas à interpretação e à aplicação das normas de direito penal material, visando à garantia dos direitos fundamentais assegurados a qualquer cidadão, tendo como fundamento a dignidade da pessoa humana (RAMIDOFF, 2017, p.35).

Um julgamento perante juízes do povo é convocado quando se está diante de crimes dolosos contra a vida, conforme prevê o artigo $5^{\circ}$, inciso XXXVIII, alínea $\mathrm{d}$ da Constituição Federal. Portanto, o Tribunal do Júri, além de (i) possuir legitimidade constitucional, enquanto órgão do Poder Judiciário apresenta como característica corolária ser (ii) composto por indivíduos advindos da sociedade e que (iii) não possuem, necessariamente, formação técnico-jurídica. E como o Júri é considerado uma instituição essencialmente democrática, o real alcance da expressão "Justiça" deve se tornar uma meta contínua nesse julgamento perante juízes do povo (BRASIL, 1988).

Portanto, tal dispositivo constitucional supracitado reforça que o real alcance da expressão "Justiça" pode ser verificado também quando se determina na Constituição que é direito de quem esteja sob acusação de cometimento de ato criminal 
doloso contra a vida ser julgado não por juízes togados, mas sim por seus próprios pares (BRASIL, 1988).

O julgamento perante juízes do povo é datado de um passado longínquo: “[...] desde a remota época de Moisés, perpassando pela Grécia, Roma, Inglaterra e outros países, até chegar às feições que constituem o Tribunal do Júri na atualidade" (OLIVEIRA, 2014, p.71). Para esse mesmo autor, o Júri, na sua atual configuração, é considerado como um instituto de cunho educativo em que a participação de membros da sociedade assessora os trabalhos do Poder Judiciário, consolidando uma Democracia, na qual o povo executa diretamente o poder que o Estado confere ao juiz togado. Dessa forma, o Júri representa um dos modos pelas quais os membros da sociedade obtêm informações sobre questões de ordem legal, bem como minimiza o espaço entre o poder estatal, executado pelo juiz togado e a população em geral.

O real alcance da expressão "Justiça" dentro dos Tribunais do Júri pode ser amplificado ou minimizado, a depender da maior ou menor incidência das influências da mídia. Esse fato é confirmado na pesquisa realizada pelo autor Oliveira (2014, p.71), o qual apregoa que:

[...] fortes indícios manifestos por casos criminais verídicos designam a mídia como decisiva influenciadora da convicção dos julgadores leigos e reveladora sensacionalista da 'barbárie' dos fatos e das condições do suposto autor do crime, desde a fase investigatória, até o momento do julgamento em plenário.

E, é esse mesmo autor quem assevera também que a imprensa apoderou para si temáticas de ordem criminal, como se as mesmas fossem mercadorias a serem exibidas nas prateleiras do supermercado, a fim de 'informar' subjetivamente a sociedade acerca da realidade dos acontecimentos fáticos da ação delitiva, acabando por destruir reputações, pessoas, famílias ou grupos de pessoas que podem nada ter a ver com o fato (OLIVEIRA, 2014).

Sabe-se que os direitos fundamentais como os de liberdade de expressão e o de imprensa, por exemplo, consagrados no artigo $5^{\circ}$, inciso IX são de extrema relevância no ordenamento jurídico pátrio (BRASIL, 1988). Entretanto, devem ser exercidos em função da plena realização do cidadão e em fina sintonia com o respeito ao princípio da dignidade humana. E, em momentos de possíveis conflitos entre distintos direitos fundamentais, a estratégia de resolução se pauta na ponderação.

$\mathrm{Na}$ ocasião em que um direito individual se tornar passível de padecimento de prejuízo que fundamente a limitação da liberdade de imprensa, tal direito individual deve se sobrepor ao de liberdade de imprensa. Por conseguinte, a proteção do direito de informar pelos meios de comunicação e das pessoas de receberem informações, deverá conceder espaço, de forma que os direitos e as garantias fundamentais, ou seja, a dignidade da pessoa humana possa prevalecer (OLIVEIRA, 2014, p.1).
A Magna Carta da República, em seu título II, cuida dos 'Direitos e Garantias Fundamentais'. A expressão 'fundamentais' equivale ao termo 'constitucionais', já que o direito fundamental, em sua origem, é aquele de fundo constitucional. [...] Em sentido amplo, a garantia significa a segurança ou o poder de usar, fruir ou obter tudo aquilo que se constitui em um direito individual ou coletivo. Do ponto de vista constitucional, a garantia é a denominação dada aos múltiplos direitos assegurados ou outorgados aos cidadãos de um país pelo texto constitucional.

Assim, no caso de julgamentos perante juízes do povo, em que tais julgamentos, bem como os próprios juízes, geralmente, sofrem mais diretamente a influência da mídia, é importante considerar que na ambiência jurídica pátria não existe direito absoluto que se anteponha aos outros de forma ilimitada, considerando que os direitos positivados na Constituição Federal, como por exemplo, o direito à privacidade e o da liberdade de expressão e de imprensa não têm fronteiras delimitadas de maneira estanque, por conseguinte, entram continuamente em embate (OLIVEIRA, 2014)

A depender da situação e do momento, o real alcance da expressão "Justiça" dentro dos Tribunais do Júri pode ser facilitado ou dificultado, quando o mesmo se torna alvo explícito da mídia (OLIVEIRA, 2014). Tais situações podem ocorrer, principalmente, quando se instalam conflitos entre os direitos fundamentais (MOSSIN, 2014). E nestes casos, objetivando solucionar conflitos entre os direitos deverão ser utilizados critérios valorativos de forma cautelosa (FACHIN, 2019).

O itinerário da justiça é o seguimento da equidade. E esta, por sua vez, no momento em que é preservada e respeitada propicia e ratifica a dignidade da pessoa humana. Nas ocasiões em que o ser humano é sujeito e objeto de respeito em sua essência, a sociedade em sua totalidade é igualmente respeitada, bem como o conjunto de valores inerentes a essa, tais como: os direitos humanos previstos no plano nacional quanto internacional (FACHIN, 2019, p.15).

Os direitos humanos não apresentam um início situado na história. Eles acompanham a própria evolução social e são na mesma medida em que ela, dinâmicos. [...] Nesse cenário, o tratamento jurídico conferido aos direitos humanos [...] é extremamente recente. Foi com a Declaração Universal dos Direitos Humanos, em 1948, que se inaugurou, de modo pioneiro, um discurso unívoco internacional sobre a proteção dos direitos humanos - e que vem sendo chamado de concepção contemporânea de direitos humanos. A partir de então se desenvolveu, no plano internacional, com reflexos nos planos constitucionais, uma nova etapa na compreensão dos direitos e na proteção das pessoas.

No que tange à análise do fato de que a ausência de um prazo estipulado em lei para duração da prisão preventiva e do processo penal afronta diversos princípios e garantias constitucionais, a qual abrange duas indagações, quais sejam: “estabelecer prazos processuais, sem qualquer punição pelo descumprimento é o mesmo que insistir na doutrina do não prazo"? e "a legislação infraconstitucional permite observância estrita ao princípio da razoável duração do processo"? Assim, 
se têm as seguintes considerações a fazer:

A Emenda Constitucional $\mathrm{n}^{\circ} 45$, de 30 de dezembro de 2004, incluiu o princípio da razoável duração do processo (BRASIL, 2004) dentro das garantias fundamentais afiançadas aos cidadãos brasileiros, como se pode verificar no artigo $5^{\circ}$, inciso LXXVIII da Constituição Federal. Neste artigo se verifica a seguinte redação: a todos, no âmbito judicial e administrativo, são assegurados a razoável duração do processo e os meios que garantam a celeridade de sua tramitação (BRASIL, 1988).

Não obstante, a legislação infraconstitucional, de forma geral, não permite observância estrita ao princípio da "razoável duração do processo". Particularmente, no sistema processual penal, essa constatação amplifica as consequências negativas para a pessoa do réu, porque o(a) cidadã(o) já se encontra na (i) eminência de ter seu direito de locomoção e de liberdade suspenso por tempo determinado ou indeterminado ou (ii) já sofrendo a efetiva suspensão de tais direitos (ROSA, 2014).

Ainda, segundo o Rosa (2014), o princípio da garantia da duração razoável do processo não se trata de novidade, pois já é discutida em diversos âmbitos, especialmente na Europa. Ademais, prevista nos documentos internacionais, embora ignorada pelo senso comum teórico.

$\mathrm{O}$ autor defende que:

Com a criminalização do cotidiano, das relações afetivas e do incremento dos tipos penais, cada vez mais nos arrostamos com o aumento do número de ações penais. $\mathrm{O}$ que pode ser um problema de gestão para alguns, externos ao processo, para os internos - acusado e vítima: a questão é de vida ou morte (ROSA, 2014, p.3).

$\mathrm{Na}$ esteira das reflexões, ainda desse mesmo autor, interessante também são as observações que faz com o fato da questão do tempo se apresentar como um paradoxo. Para o autor, o tempo não pode ser tão veloz ao ponto de impedir a reflexão, e nem tão pouco apresentar com muitas delongas podendo implicar na perda de sentido. Neste diapasão, a busca pelo razoável se defronta com as motivações dos indivíduos em situação de julgamento e com as dos atores processuais. No amálgama de perspectivas que se sobressai, no qual o processo se apresenta como palco, é comum aflorar uma verdadeira inquietude afeta aos diretamente envolvidos, particularmente aos acusados, os quais são tomados por expectativas internas (ROSA, 2014).

Por seu turno, Lopes Júnior (2014) reforça essa lamentosa assertiva ao destacar que, além da jurisprudência dar pequenos passos nesta direção, o faz de maneira tímida e sem rumo. $\mathrm{O}$ Brasil adotou a teoria do não prazo, ou seja, existem muitos prazos no Código de Processo Penal, mas completamente despidos de sanção processual, o que equivale a não ter prazo algum.

Ressalta-se a relevância da compreensão de que os indivíduos, independentemente da absolvição ou a condenação final, são possuidores do direito a razoável duração do processo, não obstante estarem na condição de reclusos, o que nesta situação a delonga é ainda mais custosa, ou em liberdade - visto que o processo por si só já se configura como uma pena (LOPES JÚNIOR, 2014).

A legislação infraconstitucional, particularmente, o Código de Processo Penal, até determina prazos, porém não explicita nenhum tipo de sanção em caso de descumprimentos. Assim, embora as legislações constitucionais e infraconstitucionais, no plano teórico se coadunam no que se refere ao direito do cidadão, em ter suas demandas judiciais resolvidas sem muitas delongas, na prática isso não ocorre. E não ocorre por dois motivos: primeiro porque as normatizações constitucionais não estipularam prazo e, segundo porque as normatizações infraconstitucionais, por sua vez, não fixaram sanções aos que não cumprissem respectivos prazos (LOPES JÚNIOR, 2014; ROSA, 2014).

Essa realidade é simplificada em uma equação matemática por Lopes Júnior (2014), prazo-sanção=ineficácia, e afirma que se faz imprescindível que o sistema jurídico de âmbito interno estabeleça demarcações ordinárias para o trâmite dos processos. E enquanto isso não ocorre, o que se verifica são consequências esvaziadas e indefinidas trazendo prejuízos à eficácia do direito fundamental, na medida em que conduz ao emprego de cláusula genérica, conteúdo vago, impreciso e indeterminado.

Caberia ao legislador fixar com exatidão: os limites temporais das medidas cautelares (e do processo penal, como um todo), bem como consagrar expressamente um dever de revisar periodicamente a medida adotada (inserido no PL 4208/2001 e vetado na Lei n ${ }^{\circ} 12.403 / 2011$ ) (LOPES JÚNIOR, 2014, p.4). O desconhecimento a respeito da duração de uma reclusão preventiva é algo preocupante e que deve ser repugnada. E a amenização de tal anseio não advém apenas da fixação de que procedimento sumário precisa ser finalizado em 30 dias, o ordinário em 60 dias, bem como a fase inicial do júri em 90 dias visto que não há sanções processuais em caso de descumprimento dos referidos prazos. Para o autor, tais prazos são desprovidos de completa eficácia equiparandose a inexistência desses. E ainda, para o autor supracitado, a amenização também tão pouco pode advir do clássico discurso de que excesso de trabalho justifica a delonga.

A indagação que permanece é: será possível estipular um limite máximo de duração dos processos? E a resposta, de acordo com Lopes Júnior (2014) é afirmativa na medida em que se adotasse como estratégia a sanção processual. Para o autor existem informações a respeito de pesquisas empíricas realizadas nas áreas da Justiça Estadual e Federal que evidenciam uma média de três anos como prazo entre o recebimento da denúncia e a sentença de primeiro grau. É fato comprovado também por estas pesquisas, de acordo com o autor supracitado, que muitos processos concluem em menor tempo e alguns outros retardam mais, entretanto o prazo médio se fixa em torno de 24 a 28 meses. Enfim, para Lopes Júnior (2014, p.6), o direito a razoável duração do processo penal se apresenta como: 
um capítulo a ser escrito no processo penal brasileiro e que deveria merecer muito mais atenção por parte das comissões de reforma do CPP, o que, infelizmente, não tem ocorrido. Precisa-se definir claramente o prazo máximo de duração das prisões cautelares e também do próprio processo penal.

No que diz respeito à reflexão sobre o fato de que o texto constitucional apenas alude ao direito de permanecer calado e o princípio da "não autoincriminação", ou "nemo tenetur se detegere" ser bastante abrangente e diante da importância de se analisar as extensões desse princípio, bem como a guarida legislativa que o defende se têm as seguintes considerações a fazer:

O princípio da "não autoincriminação", ou "nemo tenetur se detegere" abrange uma considerável gama de realidades. $\mathrm{E}$, essa não autoincriminação contempla qualquer forma de manifestação por parte da pessoa podendo ser tanto ativa, oral, documental, material. Nesse sentido, nenhum ser humano pode ser coagido por quem quer que seja (autoridade ou ainda um particular), a conceder forçosamente qualquer tipo de informação ou declaração ou dado ou objeto ou prova que direta ou indiretamente possa incriminá-lo (RAMIDOFF, 2017, p.28).

O princípio da não autoincriminação - em latim, nemo tenetur se detegere -, também conhecido como direito ao silêncio, estabelece a garantia de não se ter o dever de produzir qualquer meio de prova contra si mesmo: isto é, o agente a quem se atribui a prática de conduta delituosa não tem o dever de incriminar a si mesmo, sendo, portanto reconhecido constitucionalmente a ele o direito de permanecer calado, tanto no momento de sua prisão como durante todo o período de judicialização da instrução criminal. [...] Dessa forma, é certo que o silêncio do acusado não importará confissão nem poderá ser interpretado em prejuízo de sua defesa.

O direito de não autoincriminação é incorporado por outro direito no âmbito do processo penal, qual seja o da ampla defesa. E o direito a ampla defesa, por sua vez, abarca outras duas variáveis: (i) a autodefesa e a (ii) defesa técnica. No que se refere particularmente à autodefesa se tem ainda: (i) o direito de ser ouvido; (ii) o direito a intérprete; (iii) o direito de presença e, também, (iv) o direito de não autoincriminação (RAMIDOFF, 2017, p.26-27).

A ampla defesa [...] constitui uma das liberdades públicas mais importantes, assegurada expressamente no art. $5^{\circ}$, inciso LV da CF. A ampla defesa também pode ser identificada como uma das consequências constitucionais e legais decorrentes do princípio do devido processo legal, que garante os meios disponíveis na lei para se contrapor a acusações de condutas delituosas. É esse princípio que também garante que o indiciado, o acusado ou o réu não tenha obrigação de demonstrar a sua inocência, porém de exigir que, em razão da imputação penal que lhe for endereçada, o órgão acusador cumpra o dever de comprovar o que contra ele for alegado. [...] Em matéria processual penal, a ampla defesa assegura ao acusado o exercício pleno do direito de defesa - ainda que não estabeleça o dever legal de demonstrar sua inocência [...].

Acrescenta-se também que o direito de não autoincriminação ou nemo tenetur se detegere, além de estar contemplado dentro do direito a ampla defesa, se expressa de sete formas distintas, ou melhor dizendo, possui sete roupagens diferentes ou ainda sete direitos consequentes, quais sejam, o direito: (1) ao silêncio; (2) de não colaborar com a investigação ou com a instrução criminal; (3) de não declarar contra si mesmo; (4) de não confessar; (5) de declarar o inverídico, sem que com isso prejudique outras pessoas; (6) de não fornecer provas que interfira negativamente na sua situação jurídica; e (7) de não produzir ou de não contribuir ativamente para a produção de provas contra si mesmo (RAMIDOFF, 2017).

Não obstante, o sétimo direito consequente se desdobra em três direitos, a saber: (7.1 ou 7) de não praticar nenhum comportamento ativo que comprometa a si próprio; (7.2 ou 8) de não participar ativamente de procedimentos probatórios incriminatórios; e (7.3 ou 9) de não ceder seu corpo (total ou parcialmente) para a produção de prova incriminatória (RAMIDOFF, 2017). Pode-se afirmar, portanto, que de um único direito emanam outros nove.

A guarida legislativa que contempla o princípio do nemo tenetur se detegere pode ser encontrada no Pacto Internacional de Direitos Civis e Políticos (PIDCP) adotado pela XXI Sessão da Assembleia Geral das Nações Unidas em 16 de dezembro de 1966. O texto do referido diploma internacional foi aprovado pelo Congresso Nacional pátrio em 12 de dezembro de 1991 por meio do Decreto Legislativo $\mathrm{n}^{\mathrm{o}}$ 226. Posteriormente, por meio da entrega da Carta de Adesão ao referido Pacto, depositada em 24 de janeiro de 1992, a nação brasileira compactou seu conteúdo levando o país a declarar sua entrada em vigor em 24 de abril de 1992. Por fim, por meio do Decreto ${ }^{\circ} 592$ de 06 de julho de 1992 , a Casa Civil oficializa que o Pacto Internacional de Direitos Civis e Políticos (PIDCP) deverá ser executado e cumprido integralmente (BRASIL, 1992a).

O Pacto Internacional de Direitos Civis e Políticos (PIDCP) anexo dentro do Decreto brasileiro $n^{\circ} 592$ de 06 de julho de 1992, em seu artigo 14.3, alínea g apresenta o seguinte conteúdo: Toda pessoa acusada de um delito terá direito, em plena igualmente, a, pelo menos, as garantias de não ser obrigada a depor contra si mesma, nem a confessar-se culpada. (BRASIL, 1992a).

E ainda, a guarida legislativa que contempla o princípio da não autoincriminação pode ser encontrada também na Convenção Americana de Direitos Humanos (CADH) também conhecida como Pacto de São José da Costa Rica. Esse Tratado Internacional datado de 22 de novembro de 1969 passou a vigorar, internacionalmente, em 18 de julho de 1978. E em 25 de setembro de 1992, o Governo brasileiro depositou a carta de adesão a essa Convenção de forma que a partir desta mesma data a CADH entrou em vigor no país. Assim, por meio do Decreto no 678 de 06 de novembro de 1992 é oficializada a execução e cumprimento integral do Pacto de São José da Costa Rica em território brasileiro (BRASIL, 1992b).

$\mathrm{ACADH}$ assegura um rol de direitos muito semelhante àquele 
previsto no Pacto Internacional de Direitos Civis e Políticos, de sorte que [...] em seu art.26, a CADH determina que os Estados busquem a realização progressiva dos direitos [...] A CADH, para além de ser o instrumento de direitos humanos mais importante das Américas, apresenta disposições de caráter autoexecutório e autônomo, operando por si mesma, sem demandar a complementação por atos legislativos internos, ainda que incentive o Estado a fazê-lo a fim de expandir a proteção conferida (FACHIN, 2019, p. 134-135).

A CADH, em seu artigo 8.2, informa que qualquer indivíduo acusado de cometer delito tem direito de ser presumido como inocente durante o tempo em que não seja comprovada legalmente como culpado. Durante o processo, toda pessoa tem direito, em plena igualdade de não ser obrigado a depor contra si mesma, nem se declarar culpada (BRASIL, 1992b).

Diante do exposto, verifica-se, portanto, que qualquer que seja a especificidade da prova contra o réu que advenha ativamente dele próprio somente terá validade se a ação representar um ato voluntário e consciente de sua parte. Atitudes como ameaças morais ou físicas, pressões psicológicas, entre outras ações correlatas contra a pessoa do réu não são toleradas. Nenhuma destas atitudes contra o indivíduo é admitida e aceita para obtenção de provas (BRASIL, 1992b; FACHIN, 2019; RAMIDOFF, 2017).

A guarida legislativa que contempla o princípio da não autoincriminação pode ser encontrada também na Constituição Federal de 1988, artigo 5º inciso LXIII na seguinte declaração: “[...] o preso será informado de seus direitos, entre os quais o de permanecer calado [...]” (BRASIL, 1988).

Portanto, as considerações sobre a guarida legislativa que contempla o princípio da não autoincriminação, ou nemo tenetur se detegere estão presentes tanto no direito interno quanto no Direito Internacional (BRASIL, 1992b; FACHIN, 2019; RAMIDOFF, 2017).

Convém reforçar também que todas as dimensões do direito supramencionado incidem tanto na etapa da investigação quanto no momento da fase processual. E ainda, se aplica igualmente em qualquer outro ramo do direito seja esse trabalhista, civil, administrativo ou outro correlato, no qual a verbalização ou atitude da pessoa possa trazer como consequência uma persecução penal contra ele próprio (RAMIDOFF, 2017).

Acrescenta-se a isso, igualmente, o fato do direito a não autoincriminação não se refletir somente no âmbito do processo penal ou da investigação criminal ou civil, mas também diante de qualquer autoridade ou funcionário, de quaisquer que sejam os poderes, que elabore qualquer tipo de imputação penal (ou se suspeita) ao indivíduo. Em todas estas situações prevalece o princípio da não autoincriminação, no qual está contemplado o direito de não falar ou de não se incriminar, sem que disso possa se reverter em prejuízo ou presunção contra tal pessoa (RAMIDOFF, 2017).

Por fim, a reflexão sobre um julgamento perante juízes do povo e o real alcance da expressão "Justiça" possibilita também que se façam ponderações a respeito do princípio da inadmissibilidade das provas ilícitas, indagando-se: (i) até que ponto tal princípio pode ser considerado um valor absoluto no Direito Constitucional Brasileiro? (ii) se não, qual seria seu limite? (iii) e, em quais situações poderia ser admitida a prova obtida por meios ilícitos? E diante disso se apresentam as seguintes análises a serem ponderadas:

Anterior ao fato de dissertar sobre o princípio da inadmissibilidade das provas ilícitas serem consideradas um valor absoluto no Direito Constitucional Brasileiro é importante esclarecer que:

A Constituição de 1988 foi promulgada no Brasil como ponto final de uma era de ditadura, em que muitos direitos e garantias haviam sido suspensos ou vilipendiados. Uma inovação, portanto, quanto a esse estado de coisas em que não se tinha o processo penal guiado pela licitude, foi o princípio da inadmissibilidade de provas ilícitas. Esse princípio é derivado do devido processo legal substancial. A lei veda explicitamente a prova ilícita no inciso LVI do art. $5^{\circ}$ da $\mathrm{CF}[\ldots]$. Essa é uma garantia à própria dignidade da pessoa humana, estando, portanto, na categoria de princípio, sobrepondo-se à atuação do Estado contra o agente e impondo limites à persecução penal, ao menos no que tange a sua restrição ao previsto em lei (RAMIDOFF, 2017, p. 30-31).

A doutrina e a jurisprudência, pautando-se somente na supremacia da Constituição Federal de 1988 em seu âmbito teórico, defendem a inadmissibilidade das provas ilícitas no processo penal (RAMIDOFF, 2017). Entretanto, e não obstante postura quase unânime na sociedade jurídica brasileira, alguns autores e operadores do direito - entre esses Custódio (2011) - entende que o princípio da inadmissibilidade das provas ilícitas em casos práticos extremos não pode ser considerado um valor absoluto no Direito Constitucional Brasileiro e isso porque, em algumas situações de vultosa gravidade, os tribunais, em consonância com a compreensão assumida pelo Supremo Tribunal Federal, têm se respaldado no uso da Teoria da Proporcionalidade como forma de corrigir disformidades consequentes da utilização inflexível do preceito constitucional e assumido o emprego da prova viciada em situações que se evidenciem como favoráveis ao acusado.

Para Custódio (2011), não obstante a relevância da postura da mais alta corte brasileira, a quem de direito compete, em última instância, emitir os pareceres a respeito da normatização positivada na Carta Magna, a indicação de maior prudência interpretativa em alguns aspectos específicos seria priorizar na observação de uma determinada situação singular, a garantia constitucional que fosse mais relevante e, nestas realidades peculiares na qual a totalidade da sociedade viesse a se tornar, por exemplo, refém do crime organizado, minimizar os efeitos desse princípio constitucional.

Custódio (2011) afirma que, apesar de haver alguns autores defensores da utilização da Teoria da Proporcionalidade e o decorrente emprego de provas ilícitas, igualmente em prol da sociedade nas situações de grande monta e que ofenda a totalidade da população, como por exemplo, o tráfico ilícito de entorpecentes, os crimes do colarinho branco, o crime 
organizado, o Supremo Tribunal Federal não acatou essa tese declarando nas suas considerações que a Carta Magna não contempla essa interpretação.

Diante desse impasse, que não é pacífico na ambiência jurídica, o limite do princípio da inadmissibilidade das provas ilícitas se faria diante de situações práticas que colocassem em risco a segurança da sociedade brasileira. E, nesta mesma direção as situações nas quais poderiam ser admitidas as provas obtidas por meios ilícitos, por exemplo, seriam aquelas advindas: (i) do tráfico ilícito de entorpecentes; (ii) dos crimes do colarinho branco; e (iii) do crime organizado (CUSTÓDIO, 2011).

Portanto, em tais situações poderiam ser admitidas as provas ilícitas, porque suas consequências danosas à sociedade se configurariam como limites ao princípio em questão. Assim, os efeitos do princípio da inadmissibilidade das provas ilícitas restariam minimizados por meio do uso da Teoria da Proporcionalidade (CUSTÓDIO, 2011).

\section{Conclusão}

Pôde-se evidenciar quatro dimensões estudadas neste artigo. Primeiro se verificou que para a instituição do Júri são assegurados quatro princípios fundamentais: a plenitude de defesa, o sigilo das votações, a soberania dos veredictos e a competência para o julgamento dos crimes dolosos contra a vida. E a mídia, ao expor casos de competência do Tribunal do Júri, acaba formando os denominados "juízos paralelos”, entretanto, não se pode deixar de considerar que a liberdade de informação é direito humano universal e fundamental e extremamente essencial para a Democracia.

Segundo, a ilimitada duração da prisão preventiva e do processo penal afronta diversos princípios e garantias constitucionais. Diante disso, é importante o estabelecimento de prazos processuais, porém atrelados a alguma forma de punição pelo descumprimento, caso contrário seria o mesmo que insistir na "doutrina do não prazo".

Terceiro, apesar de texto constitucional brasileiro aludir apenas ao direito de permanecer calado, verificou-se que o princípio da "não autoincriminação", ou "nemo tenetur se detegere" é bastante abrangente em suas extensões, tendo esse ampla guarida legislativa.

E, quarto se refletiu sobre o princípio da inadmissibilidade das provas ilícitas considerado não como valor absoluto no Direito Constitucional Brasileiro, mas como possuidor de limites a depender de situações nas quais podem ou não serem admitidas provas obtidas por estes meios.
Portanto, conclui-se que retomadas contínuas de estudos sobre a temática são pertinentes na medida em que trazem luz e ampliam a compreensão da importância de se reconhecer que o julgamento perante juízes do povo se configura também como uma das importantes estratégias de busca por Justiça na ambiência jurídica.

\section{Referências}

BRASIL. Presidência da República. Constituição da República Federativa do Brasil. Brasília, DF, 1988.

BRASIL. Presidência da República. Casa Civil. Decreto n ${ }^{\circ} 592$, de 30 de julho de 1992. Dispõe sobre Atos Internacionais. Pacto Internacional sobre Direitos Civis e Políticos. Promulgação. Brasília, DF, 1992a.

BRASIL. Presidência da República. Casa Civil. Decreto n ${ }^{\circ} 678$, de 06 de novembro de 1992. Dispõe sobre a promulgação da Convenção Americana sobre Direitos Humanos (Pacto de São José da Costa Rica), de 22 de novembro de 1969. Brasília, DF, $1992 b$.

BRASIL. Presidência da República. Casa Civil. Emenda Constitucional 45, de 30 de dezembro de 2004. Dispõe sobre as alterações dos dispositivos dos arts. $5^{\circ}, 36,52,92,93,95,98,99$, 102, 103, 104, 105, 107, 109, 111, 112, 114, 115, 125, 126, 127, 128, 129, 134 e 168 da Constituição Federal, e acrescenta os arts. 103-A, 103B, 111-A e 130-A, e dá outras providências. Brasília, DF, 2004.

CUSTÓDIO, R.S. Da inadmissibilidade das provas ilícitas no Processo Penal. Rev. Jus Navigandi, v.16, n.3.067, p. 1-6, 2011.

FACHIN, M.G. (Org.). Guia de Proteção dos Direitos Humanos: sistemas internacionais e sistema constitucional. Curitiba: Intersaberes, 2019.

LOPES JÚNIOR, A. Direito à duração razoável do processo tem sido ignorado no país. Rev. Consultor Jurídico, p.1-6, 2014.

MEDEIROS, P. Uma introdução à Teoria da Democracia. Curitiba: Intersaberes, 2016.

MELLO, C.M.; MOREIRA, T. Direitos fundamentais e dignidade da pessoa humana. Rio de Janeiro: Freitas Bastos, 2015.

MOSSIN, H.A. Garantias fundamentais na área criminal. Barueri: Manole, 2014.

OLIVEIRA, C.A.S. A influência da mídia no Tribunal do Júri à luz dos princípios e garantias constitucionais que regem o Processo Penal Brasileiro. Rev. Jus Navigandi, p.1-78, 2014.

PEROVANO, D.G. Manual de metodologia da pesquisa científica. Curitiba: Intersaberes, 2016.

RAMIDOFF, M.L. Elementos de Processo Penal. Curitiba: Intersaberes, 2017.

ROSA, A.M. Duração razoável do processo sem contrapartida é como promessa de amor. Rev. Consultor Jurídico, p.1-4, 2014. 